\title{
PENGARUH LATIHAN FISIK TERHADAP KADAR GLUKOSA DARAH PENYANDANG DIABETES MELITUS TIPE 2: LITERATURE REVIEW
}

\author{
Rizka Fadhila $^{1,}$, Rima Novia Putri ${ }^{2}$ \\ 1,2 Program Studi Magister Keperawatan Kekhususan Keperawatan Medikal Bedah \\ Fakultas Ilmu Keperawatan Universitas Indonesia \\ Depok Jawa Barat Indonesia \\ Telp : 081266569668 \\ Email : chekila.rizka@gmail.com
}

\begin{abstract}
Diabetes mellitus (DM) is a metabolic disease characterized by an increase in glucose levels in the blood caused by abnormalities in insulin secretion, insulin work or can also be caused by both. Physical exercise is one of the management of diabetes mellitus that can improve and maintain optimal glycemic control so as to prevent and delay the occurrence of complications. The recommended physical exercise for people with DM includes aerobic exercise, strength training, flexibility training and balance training. The purpose of this paper is to determine the effect of physical exercise on blood glucose levels of people with DM type 2. The method of writing used is a study of literature which is examined from several journals related to the topic taken. Journals are investigated through Proquest, Ebsco, Science Direct, and Clinical Key which are then selected according to the topics to be discussed. The results obtained were a significant decrease in blood glucose in people with type 2 diabetes mellitus who did physical exercise with regard to the frequency, intensity, time and type of exercise.
\end{abstract}

Keywords : Type 2 Diabetes Mellitus, Physical exercise, Blood glucose levels

\begin{abstract}
ABSTRAK
Diabetes Melitus (DM) adalah penyakit metabolik dengan karakteristik adanya peningkatan kadar glukosa dalam darah yang diakibatkan karena kelainan sekresi insulin, kerja insulin atau dapat juga diakibatkan oleh keduanya. Latihan fisik merupakan salah satu penatalaksanaan diabetes melitus yang dapat memperbaiki dan mempertahankan kontrol glikemik yang optimal sehingga mampu mencegah dan menunda terjadinya komplikasi. Latihan fisik yang direkomendasikan untuk peyandang DM meliputi latihan aerobik, latihan kekuatan, latihan fleksibilitas dan latihan keseimbangan. Tujuan penulisan ini adalah untuk mengetahui pengaruh latihan fisik terhadap kadar glukosa darah penyandang DM tipe 2. Metode penulisan yang digunakan yaitu studi literatur yang ditelaah dari beberapa jurnal yang terkait dengan topik yang diambil. Jurnal ditelurusi melalui Proquest, Ebsco, Science Direct, dan Clinical Key yang kemudian diseleksi sesuai dengan topik yang akan dibahas. Hasil yang didapatkan yaitu adanya penurunan glukosa darah yang signifikan pada penyandang diabetes melitus tipe 2 yang melakukan latihan fisik dengan memperhatikan frekuensi, intensitas, waktu dan jenis latihannya.
\end{abstract}

Kata kunci : Dabetes Melitus tipe 2, Latihan fisik, Kadar glukosa darah

\section{PENDAHULUAN}

Diabetes Melitus (DM) merupakan penyakit tidak menular namun jumlah penyandangnya terus bertambah setiap tahun. Pada tahun 2015, penduduk dunia yang mengidap DM mencapai 415 juta jiwa dan pada tahun 2040 diperkirakan jumlah penyandang DM di dunia akan mencapai 642 juta jiwa. Diperkirakan akan terjadi peningkatan 1 dari 11 orang menjadi 1 dari 10 orang di dunia mengidap DM sampai tahun 2040 (International Diabetes Federation [IDF], 2015). 
Indonesia sebagai negara berkembang menduduki peringkat ketujuh terbesar setelah China, India, Amerika Serikat, Brazil, Rusia dan Meksiko dengan perkiraan jumlah penyandang DM sebanyak 10 juta jiwa dan diprediksi akan terus bertambah menjadi 16,2 juta jiwa pada tahun 2040 (World Health Organization [WHO], 2016). Sedangkan menurut data Riskesdas tahun 2018 prevalensi penyandang DM pada penduduk yang berusia $\geq 15$ tahun sebanyak $6,9 \%$ pada tahun 2013 dan meningkat menjadi $10,9 \%$ pada tahun 2018. Dari semua penyandang DM tersebut, $90 \%$ nya merupakan penyandang DM tipe 2 . Pada tahun 2012, hiperglikemi bertanggung jawab atas 3,7 juta jiwa kematian didunia dan diabetes menjadi beban pengeluaran kesehatan terbesar dunia yaitu sekitar 612 milyar dollar, diestimasikan sekitar $11 \%$ pembelanjaan langsung kesehatan dunia (WHO, 2016).

Diabetes melitus tipe 2 tidak bisa disembuhkan namun kadar glukosa darah dapat dipertahankan dalam batas normal untuk mencegah terjadi komplikasi yang sifatnya akut maupun kronik. Komplikasi yang muncul pada pasien DM tipe 2 meliputi komplikasi mikrovaskular seperti retinopati, nefropati, dan neuropati sedangkan komplikasi makrovaskular seperti penyakit jantung iskemik, peripheral artery disease (PAD) dan penyakit cerebrovaskuler. Berbagai komplikasi yang muncul inilah yang menjadi pemicu meningkatnya angka kesakitan dan kematian pada penyandang DM tipe 2. Apabila komplikasi telah terjadi maka akan sangat sulit untuk mengembalikan ke kondisi normal karena gangguan yang terjadi bersifat permanen. Oleh karena itu sangat dibutuhkan upaya untuk mencegah terjadinya komplikasi (Soegondo, 2018).

Tujuan utama penanganan DM tipe 2 adalah untuk mengontrol kadar glukosa darah dan mencegah atau memperlambat terjadinya komplikasi sehingga berbagai intervensi untuk mengontrol glukosa darah sudah banyak dikembangkan. Perkeni (2015) mengatakan bahwa terdapat empat langkah dalam penatalaksanaan DMT2 meliputi nutrisi, edukasi, latihan fisik dan terapi farmakologi. Pelaksanaan keempat langkah ini memerlukan peran serta berbagai tenaga kesehatan seperti nutrisionist, perawat, dokter dan tenaga kesehatan lainnya. Disamping itu kerjasama pasien beserta keluarga juga memiliki andil yang sangat penting sebagai upaya untuk mencegah atau memperlambat terjadi komplikasi dan meningkatkan kualitas hidup penyandang DM tipe 2 sehingga perlu diberikan penjelasan dan pengetahuan tentang diabetes.

Beberapa bukti ilmiah telah banyak menunjukkan bahwa latihan fisik dapat membantu mencegah dan meperlambat onset penyakit DMT2 serta mengontrol kadar gula darah. Suatu penelitian di Finlandia menunjukkan bahwa kelompok intervensi dengan latihan fisik minimal 30 menit setiap hari dengan intensitas sedang terjadi penurunan $39 \%$ terhadap risiko terjadinya diabetes (Lindstrom et al, 2013). Penelitian di Amerika oleh Knowler yang melibatkan 3234 subyek penelitian dengan intoleransi glukosa menunjukkan bahwa pada akhir penelitian kelompok dengan intervensi latihan fisik intensitas sedang selama 150 menit seminggu dapat mengurangi risiko terjadinya diabetes $58 \%$ dibandingkan dengan kelompok yang mendapatkan intervensi merformin.

\section{METODE}

Metode penulisan yang digunakan yaitu studi literatur yang ditelaah dari beberapa jurnal terkait dengan topik yang diambil yaitu tentang pengaruh latihan fisik terhadap kadar glukosa darah penyandang diabetes melitus tipe 2. Jurnal ditelurusi melalui Proquest, 
Ebsco, Science Direct, dan Clinical Key kemudian diseleksi sesuai dengan topik yang akan dibahas. Pembatasan proses pencarian tidak hanya dikaitkan dengan tema, namun juga tahun diterbitkannya jurnal tersebut. Jurnal yang dipakai yang terbit 10 tahun terakhir. Kata kunci pencarian yaitu diabetes melitus tipe 2, latihan fisik dan kadar glukosa darah.

\section{HASIL DAN PEMBAHASAN}

Secara umum, aktifitas fisik yang dilaksanakan secara konsisten mempunyai efek terhadap perubahan fisiologi dan adaptasi dalam tubuh manusia. Aktifitas fisik diartikan sebagai setiap gerakan tubuh yang ditimbulkan oleh otot skletal yang menghasilkan pengeluaran energi yang dapat diukur dalam kilokalori (Duclos et al., 2013). Latihan fisik merupakan salah satu jenis dari aktifitas fisik. Latihan fisik adalah gerakan tubuh yang dilakukan otot dengan terencana, terstruktur, berulang yang menyebabkan peningkatan pemakaian energi dengan tujuan meningkatkan kebugaran tubuh. Latihan fisik sering dijadikan sebagai langkah pertama modifikasi gaya hidup dalam pencegahan dan penanganan penyakit kronis termasuk DM tipe 2 (Pan et al., 2018).

Secara umum terdapat beberapa jenis latihan fisik yang direkomendasikan untuk penyandang DM tipe 2 diantaranya latihan aerobik, latihan kekuatan, latihan fleksibilitas dan latihan keseimbangan.

Latihan aerobik adalah latihan fisik yang memiliki ritme, pengulangan dan kesinambungan gerak pada otot yang besar. Frekuensi latihan aerobik yang direkomendasikan untuk penyandang DMT2 yaitu minimal dilakukan 3 kali seminggu dengan jarak antar latihan tidak boleh lebih dari 2 hari berturutturut. Hal ini dikarenakan efek latihan yang hanya bersifat akut atau sementara dalam memperbaiki aktifitas insulin. Latihan aerobik untuk penyandang
DMT2 minimal dengan intensitas sedang yaitu $70 \%$ denyut nadi maksimal dengan durasi 150 menit perminggu.. Yang termasuk dalam jenis latihan aerobik antara lain renang, jalan cepat dan bersepeda (Balducci, 2014).

Latihan kekuatan direkomendasikan dilakukan minimal 2 sesi per minggu namun akan lebih baik jika dilakukan 3 sesi per minggu. Latihan ini merupakan bagian dari program latihan fisik untuk penyandang DMT2 yang dilakukan bersamaan dengan latihan aerobik. Intensitas yang disarankan yaitu intensitas sedang yang mencapai $70 \%$ denyut nadi maksimal agar mendapatkan manfaat yang optimal dalam meningkatkan aktifitas insulin. Dalam satu sesi latihan ketahanan minimal meliputi 5-10 gerakan latihan yang melibatkan kelompok otot utama. Dalam satu gerakan latihan dilakukan pengulangan 10-15 kali (1 set) di awal latihan, kemudian berat beban dapat ditingkatkan seiring berjalannya waktu. Agar kekuatan otot dapat meningkat secara optimal maka latihan ketahanan dapat dilakukan minimal 3-4 set atau mendekati kelelahan. Jenis latihan ini antara lain dumb bells dan barbell (Balducci, 2014).

Latihan fleksibilitas merupakan bagian dari program latihan fisik yang dapat dilakukan oleh penyandang DMT2 tetapi latihan ini tidak untuk menggantikan latihan yang lain. Latihan ini disarankan untuk penyandang DMT2 yang sedang menjalani perawatan, tidak biasa melakukan latihan fisik, beresiko jatuh, lanjut usia dan mengalami kecacatan. Frekuensi latihan fleksibilitas yang direkomendasikan yaitu 2-3 kali dalam seminggu dengan 3-10 kali pengulangan dalam setiap gerakan dengan durasi berapa saja tergantung kemampuan individu. Latihan fleksibilitas dilakukan dengan intensitas ringan yaitu mencapai $50 \%$ denyut nadi maksimal. Jenis latihan ini antara lain yaitu latihan peregangan dan latihan 
rentang gerak sendi. Latihan fleksibilitas penting dilakukan oleh penyandang DMT2 untuk mencegah terjadi keterbatasan dan gerakan sendi dan untuk melancarkan aliran darah (Colberg et al, 2016; Duclos, 2013; Kurniawan, 2016). Untuk mencapai tujuan, maka latihan fleksibilitas harus dilakukan secara teratur dan berkelanjutan serta melakukan pengingkatan frekuensi dan durasi secara bertahap.

Latihan keseimbangan sebagai salah satu tipe dari latihan fisik bermanfaat untuk memperbaiki gaya berjalan, meningkatkan keseimbangan dan mengurangi resiko jatuh bahkan ketika neuropati sudah terjadi. Contoh latihan keseimbangan antara lain latihan berdiri dengan satu kaki dan latihan menggunakan alat keseimbangan. Intensitas latihan keseimbangan yang direkomendasikan yaitu intensitas sedang dengan 2-4 kali pengulangan setiap gerakan dan dilakukan penahanan selama 10-30 detik dengan frekuensi 23 kali dalam seminggu. Latihan keseimbangan dapat dilakukan dalam durasi berapa saja sesuai dengan kemampuan individu (Colberg et al, 2016). Untuk mendapatkan hasil yang optimal maka latihan keseimbangan harus dilakukan secara teratur dan dilakukan peningkatan durasi dan frekuensi secara bertahap.

Latihan yoga dan tai chi merupakan kombinasi dari latihan fleksibilitas, keseimbangan dan ketahanan juga dapat memperbaiki kontrol glikemik dan menurunkan resiko jatuh sampai $28 \%$ (Gillespie et al, 2012). Disamping itu latihan ini juga dapat meningkatkan kualitas hidup penyandang DMT2 (Colberg et al, 2016).

Pada penyandang DM tipe 2, latihan fisik berperan penting dalam mengatur kontrol glikemik yang optimal. Resistensi insulin yang merupakan masalah utama tidak dapat membantu perpindahan glukosa ke dalam sel namun ketika melakukan latihan fisik maka otot akan berkontraksi sehingga memiliki sifat seperti insulin dan permeabilitas membran terhadap glukosa meningkat. Hal ini menyebabkan resistensi terhadap insulin berkurang dan sebaliknya sensitifitas insulin meningkat sehingga kebutuhan insulin pada penyandang DMT2 akan berkurang. Respon ini akan terjadi setiap melakukan latihan fisik namun ini bukan merupakan efek yang menetap atau berlangsung lama, oleh karena itu latihan fisik harus dilakukan secara terus menerus dan teratur (Duclos et al, 2013).

Disamping itu kontraksi otot juga dapat merangsang masuknya glucose transporter-4 (GLUT 4) ke membran plasma sel otot yang aktif walaupun dalam kondisi tidak ada insulin. GLUT 4 merupakan senyawa asam amino yang sangat banyak terdapat dalam jaringan yang akan menyerap glukosa dari darah. Pengaruh latihan fisik ini akan bertahan selama 24-72 jam, oleh sebab itu latihan secara teratur penting untuk meningkatkan sensitivitas insulin jangka panjang (Duclos et al, 2013). Pengaruh yang ditimbulkan dari latihan fisik tidak selalu sama pada setiap individu terhadap penurunan kadar glukosa darah, tergantung kepada intensitas, durasi, jenis dan frekuensi latihan (Soegondo, 2018). Disamping itu kadar glukosa darah penyandang DM tipe 2 juga dipengaruhi oleh hal-hal lain seperti tingkat stres, obesitas, asupan makanan, jenis pengobatan, aktifitas fisik, lamanya menderita diabetes dan penyakit penyerta (Bazaef, 2013; Harris, 2018; Kakade, 2018; Khattab et al, 2010).

Latihan fisik yang teratur dapat meningkatkan sensitifitas insulin otot pada individu dengan prediabetes maupun diabetes melitus tipe 2. Bahkan latihan dengan intensitas rendah sekalipun dapat meningkatkan kerja insulin pada orang dewasa yang sebelumnya tidak aktif. Namun pada individu dengan resistensi insulin yang 
lebih tinggi direkomendasikan untuk meningkatkan frekuensi, intensitas dan durasi latihan fisiknya.

Disamping sebagai kontrol glikemik, latihan fisik juga bermanfaat untuk menurunkan kadar lemak darah, tekanan darah, kadar kolesterol jahat (LDL) dan menurunkan berat badan serta meningkatkan kadar kolesterol baik (HDL), melancarkan peredaran darah, dan mencegah komplikasi tergantung kepada frekuensi, intensitas, durasi dan tipe latihan fisik yang disesuaikan dengan waktu, tempat, preferensi, minat serta kondisi pasien (Duclos et al, 2013; Soegondo,2018 ).

Meta analisis yang dilakukan oleh Sanzs (2010) terdiri dari 14 randomized controlled trials melibatkan 377 penyandang DM dengan durasi latihan fisik bervariasi setiap sesi antara 30 sampai 120 menit, membuktikan bahwa latihan fisik secara signifikan meningkatkan kontrol glikemik yaitu menurunkan glycated haemoglobin.

Penelitian eksperimen yang dilakukan oleh Nelson et al pada tahun 2010 di Amerika membuktikan bahwa 20 menit peregangan pasif merupakan salah satu latihan fisik dapat menurunkan kadar glukosa darah pada populasi beresiko DM dan yang telah terdiagnosa DM. Penelitian dilakukan pada 22 orang dewasa dengan resiko tinggi DM dan yang telah terdiagnosa DM. Responden diberikan 43 gram karbohidrat, 2 jam setelah itu dilakukan pemeriksaan kadar glukosa darah. Kemudian setelah 30 menit dilakukan latihan peregangan pasif selama 20 menit dan kemudian dilakukan pemeriksaan kadar glukosa setelah latihan. Hasil nya membuktikan bahwa peregangan pasif secara signifikan dapat menurunkan kadar glukosa darah responden kelompok intervensi.

Penelitian lain dilakukan oleh Park et al tahun 2014 di Korea menyatakan bahwa latihan fleksibilitas berupa peregangan pasif secara signifikan dapat menurunkan kadar $\mathrm{HbA1c}$ penyandang
DMT2. Penelitian dilakukan pada 15 responden yang terdiri dari 8 pria dan 7 wanita. Responden dibagi menjadi kelompok intervensi dan kelompok kontrol. Kadar HbA1c diukur sebelum latihan dan 8 minggu setelah latihan berturut-turut. Hasil penelitian membuktikan bahwa kadar HbAlc menurun secara signifikan pada kelompok intervensi dan terjadi perbedaan kadar HbA1c yang signifikan antara kelompok kontrol dan kelompok intervensi.

Penelitian yang dilakukan oleh Taheri et al di Korea pada tahun 2018 juga membuktikan bahwa peregangan pasif pada penyandang DM tipe 2 dapat menurunkan kadar glukosa darah. Penelitian ini dilakukan pada 50 orang penyandang DM tipe 2 yang dibagi menjadi kelompok kontrol dan kelompok intervensi. Pada kelompok intervensi dilakukan peregangan pasif selama 20 menit kemudian dilakukan pengukuran kadar glukosa darah segera setelah latihan, 20 menit setelah latihan dan 1 jam setelah latihan. Hasil yang didapatkan, kadar glukosa menurun secara signifikan segera setelah latihan, 20 menit setelah latihan dan 1 jam setelah latihan. Sedangkan pada kelompok kontrol tidak terdapat penurunan kadar glukosa darah secara signifikan (Taheri, et al, 2018).

Prinsip latihan fisik pada penyandang DMT tipe 2 sama dengan prinsip latihan fisik secara umum, yaitu harus memenuhi FITT (Frequency, Intensities, Time, Type). Frekuensi yaitu jumlah latihan fisik yang harus dilakukan dilakukan perminggu dimana sebaiknya dilakukan secara teratur 3-5 kali perminggu dengan total waktu 120150 menit. Intensitas yaitu terkait dengan ringan,sedang ataupun beratnya latihan yang dilakukan. Hal ini dapat ditentukan berdasarkan penentuan denyut nadi maksimal (DNM). DNM adalah 220-umur pasien. Untuk intensitas latihan ringan-sedang diharapkan mencapai 50-70\% DNM 
yang disebut dengan denyut nadi sasaran (DNS). Ini artinya selama melakukan latihan fisik denyut nadi penyandang DM harus mencapai DNS namun tidak boleh melebihinya. Time (durasi) melakukan latihan yang direkomendasikan yaitu 30-60 menit. Tipe latihan yaitu berkaitan dengan jenis latihan yang dilakukan seperti latihan aerobik, latihan kekuatan,latihan fleksibilitas dan latihan keseimbangan (Duclos, et al 2013; Soegondo,2018).

Penyandang DM tipe 2 dalam melakukan latihan fisik sebaiknya berada dalam pengawasan. Keluhan yang dirasakan oleh penyandang DMT2 selama latihan fisik dapat dijadikan sebagai indikator apakah latihan bisa dilanjutkan atau harus dihentikan. Apabila pada pemeriksaan awal kadar glukosa darah penyandang DM tipe 2 $<100 \mathrm{mg} / \mathrm{dl}$ sebaiknya diberikan karbohidrat terlebih dahulu untuk mencegah hipoglikemia sedangkan apabila kadar glukosa darah $>250 \mathrm{mg} / \mathrm{dl}$ sebaiknya tidak dilakukan latihan fisik dan menunggu hingga kadar glukosa darah stabil karena dapat meningkatkan kadar glukosa darah dengan cepat ketika memulai latihan dan akan menyebabkan terjadinya ketosis. Begitu juga yang terjadi apabila penyandang DM tipe 2 melakukan latihan yang berat walaupun dalam waktu yang singkat. Oleh karena itu perlu dilakukan pemeriksaan kadar glukosa darah sebelum dan setelah latihan fisik. Pemeriksaan kadar glukosa darah ini sangat dianjurkan untuk penyandang DM tipe 2 yang baru pertama kali melakukan latihan fisik, penyandang DM tipe 2 yang merasa glukosa darahnya turun, dan penyandang DM tipe 2 yang melakukan latihan fisik lebih dari 1 jam. Disamping itu penyandang DM tipe 2 tidak dianjurkan melakukan latihan fisik apabila sesak napas, cedera berat, pusing, tekanan darah tidak normal, lemas, mata kabur, nyeri dada, leher, bahu dan rahang (Ilyas, 2018).
Sebuah penelitian menyatakan bahwa latihan aerobik, latihan kekuatan ataupun kombinasi keduanya dengan pengawasan tenaga terlatih menunjukkan peningkatan kadar $\mathrm{HbA1c}$ dibandingkan dengan latihan yang dilakukan tanpa pengawasan. Namun, terdapat perubahan yang kurang berarti dalam hal penurunan berat badan, dimana tidak ada perbedaan antara kombinasi latihan aerobik dengan latihan kekuatan yang diawasi ataupun yang tidak diawasi (Pan et al., 2018).

Disamping dapat menurunkan kadar glukosa darah, latihan fisik juga dapat menurunkan resiko kejadian diabetes melitus. Hal ini sejalan dengan penelitian di Finlandia yang menunjukkan bahwa kelompok intervensi dengan latihan fisik minimal 30 menit setiap hari dengan intensitas sedang terjadi penurunan $39 \%$ terhadap risiko terjadinya diabetes (Lindstrom et al, 2013). Balducci et al (2014) dalam review article mengatakan bahwa latihan fisik mempunyai pengaruh positif terhadap penyandang DM tipe 2 . Latihan fisik merupakan manajemen utama DM tipe 2 untuk membantu mencapai dan mempertahankan tujuan terapeutik serta meningkatkan kualitas hidup.

Agar penyandang DMT2 merasakan manfaat dari latihan fisik maka dilakukan evaluasi dengan membandingkan hasil pemeriksaan awal dengan pemeriksaan setelah latihan. Evaluasi ini juga bisa dilakukan setelah 3-4 bulan apabila penyandang DMT2 melakukan latihan fisik secara teratur. Hasil evaluasi secara berkala ini dapat digunakan untuk memantau ketepatan program latihan dan untuk melihat kemajuan latihan dengan membandingkan dengan pemeriksaan awal (Soegondo, 2018).

\section{KESIMPULAN}

Dari beberapa jurnal yang telah ditelaah, didapatkan kesimpulan bahwa latihan fisik yang dilakukan secara 
teratur dan memperhatikan prinsip FITT (Frequency, Intensities, Time, Type) dapat menurunkan kadar glukosa darah penyandang diabetes melitus tipe 2 . Terdapat beberapa jenis latihan fisik yang direkomendasikan untuk penyandang DM tipe 2 diantaranya yaitu latihan aerobik, latihan kekuatan, latihan fleksibilitas dan latihan keseimbangan.

\section{UCAPAN TERIMA KASIH}

Terimakasih yang tak terhingga penulis sampaikan kepada Fakultas Ilmu Keperawatan Universitas Indonesia yang telah memfasilitasi dan membekali penulis dengan ilmu pengetahuan sehingga penulis dapat menyelesaikan tinjauan literature ini.

\section{DAFTAR PUSTAKA}

Balducci, S., Sacchetti, M., Orlando, G., Errico, V. D., Fallucca, S., Menini, S., \& Pugliese, G. (2014). Physical exercise as therapy for type 2 diabetes mellitus, 30 (October 2013), 13-23. https://doi.org/10.1002/dmrr

Bazaev, N. A., Pletenev, A. N., \& Pozhar, K. V. (2013). Classification of Factors Affecting Blood Glucose Concentration Dynamics, 47(2), 100-101.

Colberg, S. R., Sigal, R. J., Yardley, J. E., Riddell, M. C., Dunstan, D. W., Dempsey, P. C., Tate, D. F. (2016). Physical Activity/Exercise and Diabetes: A Position Statement of the American Diabetes Association, 39(November), 2065-2079. https://doi.org/10.2337/dc16-1728

Duclos, M., Oppert, J., Verges, B., Coliche, V., Gautier, J., Guezennec, Y., Strauch, G. (2018). Physical activity and type 2 diabetes . Recommandations of the SFD ( Francophone Diabetes Society ) diabetes and physical activity working group $\Sigma$.
Diabetes and Metabolism, 39(3) 205216.https://doi.org/10. 1016/j.diabet.2013. 03.005

Gillespie,L.D., Robertsson, M.C., Gillespie,W.J., Sherrington,C., Gates,S., Clemsojn, L.M., Lamb,S.E. (2012). Interventions for preventing falls in older people living in the community. Cochrane database syst rev. 2012 Sep 12;(9):CD007146. doi: 10.1002/14651858.CD007146.pu b3,.

Harris, M. L., Oldmeadow, C., Hure, A., Luu, J., Loxton, D., \& Attia, J. (2017). Stress increases the risk of type 2 diabetes onset in women : A 12-year longitudinal study using causal modelling, 1-14. https://doi.org/

10.1371/journal.pone.0172126

Ilyas, E.I., (2018). Olahraga bagi Diabetisi dalam dalam Soegondo, S., Soewondo, P., \& Subekti. Ed. Penatalaksanaan Diabetes Mellitus Terpadu. Jakarta: FK UI. International Diabetes Federation (IDF). (2016) Global Guideline for Managing Older People With Type 2 Diabetes.

Kakade, A. A., Mohanty, I. R., \& Rai, S. (2018). Assessment of factors associated with poor glycemic control among patients with Type II Diabetes mellitus, 4(3), 1-6. https://doi.org/10.15761/IOD.100 0209

Kemenkes RI. (2018). Riset Kesehatan Dasar; RISKESDAS. Jakarta: Balitbang Kemenkes RI

Khattab, M., Khader, Y. S., Alkhawaldeh, A., \& Ajlouni, K. (2010). Factors associated with poor glycemic control among patients with Type 2 diabetes. Journal of Diabetes and Its Complications, 24(2), 84-89. https://doi.org/10.1016/j.jdiacomp .2008.12.008

Kurniawan, A. A., \& Wuryaningsih, Y. N. S. (2016). Physical Exercise 
Recommendations for Type 2 Diabetes. Berkala Ilmiah Kedokteran Duta Wacana, 01, 197-208.

Lindstrom J, Peltonen M, Eriksson JG, et al. Improved lifestyle and decreased diabetes risk over 13 years : long-term follow-up ot the randomised Finnish Diabetes Prevention Study (DPS).Diabetologia. 2013;56(2):284-293.

Nelson, A. G., Kokkonen, J., \& Arnall, D. A. (2011). Twenty minutes of passive stretching lowers glucose levels in an at-risk population: an experimental study. Journal of Physiotherapy, 57(3), 173-178. https://doi.org/ 10.1016/S18369553(11)70038-8

Pan, B., Ge, L., Xun, Y., Chen, Y., Gao, C., Han, X., ... Shan, H. (2018). Exercise training modalities in patients with type 2 diabetes mellitus : a systematic review and network meta-analysis, 1-14.

Park, S. H. (2015). Effects of passive static stretching on blood glucose levels in patients with type 2 diabetes mellitus. The Society of Physical Therapy Science, 27(5), 1463-1465.
PERKENI. (2015). Konsensus pengelolaan dan pencegahan diabetes mellitus tipe 2 di Indonesia . Jakarta : Perkumpulan Endokrinologi Indonesia.

Sanz, C., Gautier, J., \& Hanaire, H. (2018). Physical exercise for the prevention and treatment of type 2 diabetes. Diabetes and Metabolism, 36(5), 346-351. https://doi.org/10.1016/j.diabet. 2010.06.001

Soegondo., Soewondo., Subekti., (2018). Penatalaksaan Diabetes Melitus Terpadu. Jakarta : FKUI

Taheri, N., Mohammadi, H. K., Ardakani, G. J., \& Heshmatipour, M. (2018). The effects of passive stretching on the blood glucose levels of patients with type 2 diabetes. Journal of Bodywork and Movement Therapies, 1-5. https://doi.org/10.1016/j.jbmt. 2018.02.009

WHO (2016). Diabetes Program: diabetes action, cronic disease and helath promotion diabetes unit Switzerland. http://www.who.int/diabetes/actio n. 